\title{
The Associations Between Media Use, Midpoint of Sleep, and Sleep Quality in German Preschoolers: A Mediation Analysis Based on the Ulm SPATZ Health Study
}

\author{
Cristian Ricci ${ }^{1}$ \\ Tanja Poulain ${ }^{2,3}$ \\ Dietrich Rothenbacher ${ }^{4}$ \\ Jon Genuneit (D) ${ }^{1,4}$ \\ 'Pediatric Epidemiology, Department of \\ Pediatrics, Medical Faculty, Leipzig \\ University, Leipzig, Germany; ${ }^{2}$ LIFE \\ Leipzig Research Center for Civilization \\ Diseases, Leipzig University, Leipzig, \\ Germany; ${ }^{3}$ Department of Women and \\ Child Health, Hospital for Children and \\ Adolescents and Center for Pediatric \\ Research (CPL), Leipzig University, \\ Leipzig, Germany; ${ }^{4}$ Institute of \\ Epidemiology and Medical Biometry, Ulm \\ University, Ulm, Germany
}

Introduction: The relation of electronic media use with sleep quality among preschoolers is a matter of ongoing debate. Longitudinal data are scarce and do not account for sleeping schedules.

Methods: We used the German Children's Sleep Habits Questionnaire to measure parentreported child's sleep quality; its score is computed by the sum of 34 items defined by a 1-3 level Likert scale (score ranging 34-102), with higher values representing lower sleep quality. A causal mediation analysis of these relations using data from the Ulm SPATZ Health Study in Germany was conducted. Repeated data on electronic media use, book reading, sleep quality, sleep duration, and midpoint of sleep were prospectively collected yearly from ages 4 to 6 years $(n=563)$ during parent's working days and free days.

Results: We observed negative correlations of sleep quality with sleep duration and midpoint of sleep at ages $4-5(\mathrm{R}=-0.21$ to -0.10$)$, which attenuated with age 6 years. Sleep duration and midpoint of sleep were strongly positively correlated at all ages $(\mathrm{R}=0.55-0.95)$. We observed significant negative associations between total electronic media use and TV/DVD watching, while book reading did neither affect the sleep quality score nor sleep duration or midpoint of sleep. We found little evidence for an indirect negative effect of media use on sleep quality via sleep duration or midpoint of sleep, indicating that media use acts independently on sleep duration, midpoint of sleep, and sleep quality. Non-statistically significant associations of sleep duration and midpoint of sleep on sleep quality indicate that these are independent aspects of sleep adequacy. Evidence for this was stronger during free days.

Conclusion: Media use acted on sleep quality through a direct effect in a prospective fashion. Thus, we conclude that electronic media use increases the risk for sleep impairments in German preschoolers, while book reading seems to be a safe and healthy alternative.

Keywords: digital media, books, sleep quality, sleep duration, midpoint of sleep, mediation analysis

\section{Introduction}

Healthy sleep represents an essential part of a healthy lifestyle for all ages. In children, adequate sleep is related to better school performance, improved attention and better physical health. ${ }^{1}$ Therefore, research into pediatric sleep health is a field of growing interest yet rich in adversities and challenges. ${ }^{2}$ Of note, measuring sleep adequacy is particularly difficult since it is a complex concept
Correspondence: Cristian Ricci Pediatric Epidemiology, Department of Pediatrics, Medical Faculty, Leipzig University, Liebigstraße 20a, Haus 6 Leipzig, 04103, Germany

Tel +4934I 9724182

$\mathrm{Fax}+493419728210$

Email cristian.ricci@medizin.uni-leipzig.de 
defined by a network of interconnected factors with useful dimensions including sleep quality and quantity. ${ }^{3} \mathrm{On}$ the one hand, children's sleep quality can be evaluated by certain proxies, such as frequency of episodes of parasomnias, difficulties to fall asleep or daytime sleepiness. ${ }^{4}$ On the other hand, sleep quantity can be defined as sleep duration, per se. Finally, another matter of interest in child sleep health is the chronotype, which is a biological feature that is difficult to measure. Underlying this concept is the circadian rhythm that influences sleep adequacy and determines the child's preference to sleep at a particular time. Its role in child sleep health, as well as the extent to which sleep quality, sleep quantity, and chronotype are interconnected, is a matter of ongoing debate. ${ }^{3}$ There is an increasing body of evidence showing that sleep may represent a relevant health issue for preschoolers. Moreover, sleep issues in young children are known to be some of the most common problems that parents report to their pediatricians. ${ }^{5}$ Furthermore, it appears that preschoolers have some specific sleeping problems, compared to older children and adolescents, with higher prevalence of parasomnias and awakening due to fears as for specific determinants of sleep problems. ${ }^{6}$ Finally, sleep issues in children likely influence behavior which in turn represents a relevant public health threat with increasing related costs. ${ }^{7}$

Numerous factors contribute to sleep adequacy in school-age children and robust evidence points towards a relation between electronic media use, poor sleep quality and inadequate sleep quantity in children and adolescents between 6 and 18 years. ${ }^{8-10}$ However, media use is nowadays also becoming more common in preschoolers, which increases the demand for research aimed at investigating how media use influences sleep adequacy in this critical age period. ${ }^{11,12}$

So far, existing evidence regarding the investigation into child sleep health is mostly of cross-sectional nature, while prospective studies with adequate sample size are scarce. ${ }^{13-20}$ Moreover, media use has been shown to impact sleep duration and may thus also shift the midpoint of sleep..$^{21}$ However, we are unaware of any study investigating whether these effects drive subsequent impairment of sleep quality in preschoolers.

In the present work, data from the Ulm SPATZ Health Study have been used to evaluate the relation between media use and sleep quality in German preschoolers. To achieve this, the prospective design of SPATZ was exploited using a causal mediation analysis with sleep duration and midpoint of sleep as mediators of the relation between media use and sleep quality. This approach was chosen according to five different objectives. We aimed to evaluate: (1) if preschooler's midpoint of sleep, quantity, and quality of sleep are independently related to media use or if these factors are related in a causal network with mediated indirect effects; (2) the relation between media use and sleep quality in preschoolers; and (3) if this relation is consistent or may change between four and six years of age. Furthermore, it is widely acknowledged that digital media use is an inferior entertainment for preschool children. ${ }^{1}$ Thus, we evaluated (4) how book reading, instead of electronic media use, may have influenced sleep quality and (5) to what extent parental working activities and/or daycare determined the mediation effect of sleep duration and midpoint of sleep for the relation between electronic media use and book reading on sleep quality.

\section{Materials and Methods The UIm SPATZ Health Study}

The Ulm SPATZ Health Study is an ongoing prospective birth cohort study with repeated measures based on 1006 children consecutively recruited after their birth between April 2012 and May 2013 at the University Medical Center Ulm, Southern Germany. Following a baseline assessment shortly after delivery, the participating families received self-administered written questionnaires yearly at the child's birthday. Participation in SPATZ was completely voluntary and informed consent was collected from all parents. The present results are based on the waves at the children's ages of 4, 5, and 6 years. Ethical approval was obtained from the ethical review board of Ulm University (No. 311/11). The SPATZ study was conducted in agreement with the Declaration of Helsinki.

\section{Assessment of Child Sleep Quality}

The overall score of the German version of the Children's Sleep Habits Questionnaire (CSHQ) was used to measure parent-reported child's sleep quality during a typical week. The CSHQ is a multidimensional questionnaire in which parents are asked about bedtime resistance, sleep onset delay, sleep duration, sleep anxiety, night waking, parasomnias, sleep-disordered breathing, and daytime sleepiness. The CSHQ total score is computed by the sum of 34 items scored by a 3-level Likert scale. Thus, the CSHQ score ranges between 34 and 102 with higher values 
representing lower sleep quality. The CSHQ questionnaire was validated in German children aged 4 to 10 years. ${ }^{22}$ The CSHQ score was used as a continuous variable. This choice was taken according to the explorative nature of our study and considering higher model efficiency to detect associations.

\section{Assessment of Digital Media Use and Book Reading}

Parents were asked about the time spent by their child with electronic media and book reading on weekends and parents' working days using a six-point Likert scale with items coded as: never; up to $1 \mathrm{~h} /$ day; 1 to $<2 \mathrm{~h} /$ day, 2 to $<3 \mathrm{~h} /$ day, 3 to $<4 \mathrm{~h} /$ day and $\geq 4 \mathrm{~h} /$ day. Time spent watching TV or DVD (also via PC/laptop or Smartphone) as passive activities in front of a screen, and time actively spent using computer, tablets or smartphones were considered separately. In addition, cumulative time spent using electronic media, actively and passively, was also considered. A further variable considering time spent in self- or parent-assisted book reading was computed.

\section{Assessment of Sleeping Characteristics}

Sleep duration and midpoint of sleep of the SPATZ participants were reported by parents using the Child Chronotype Questionnaire. ${ }^{23}$ Sleep duration was computed as the difference between wake-up time and sleep onset.
Midpoint of sleep was computed as the sum of sleep onset and half of the sleep duration. Notably, sleep onset was computed as the time at which a subject goes to bed plus sleep latency, which in turn is the time taken to fall asleep. Data regarding free days and parents' working days were collected.

\section{Statistical Analysis}

Sleep quality scores, electronic media use, book reading, sleep duration and midpoint of sleep were described by study wave, and for weekends and free days, using medians and 10th to 90th percentiles. A linear trend test over waves was performed by means of a Wald $t$-test applied to the slope of the relation between the aforementioned variables, considered as outcome, and a covariate coding for the study wave (Table 1). All variables were converted to normalized Z-scores using Blom's inverse rank transformation. ${ }^{24}$ This approach was chosen to reduce variable skewness and to compute standardized regression coefficients, rescaled in a range between -1 and 1 . Notably, this enhances model interpretability since the regression coefficients can be interpreted as the percentage of explained variance $(0.1$ will be $10 \%)$. Heat maps depict Pearson correlation coefficients of Blom's transformed variables within and between different time points.

A mediation analysis was performed in the form of a causal path model having sleep duration or midpoint of

Table I Sleep Quality Score and Media Use of SPATZ Children at Different Time Points

\begin{tabular}{|c|c|c|c|c|}
\hline & Wave 6 (Age 4) & Wave 7 (Age 5) & Wave 8 (Age 6) & $\mathbf{P}_{\text {trend }}$ \\
\hline Sleep quality score & $43(37,53)$ & $43(36,52)$ & $42(36,52)$ & 0.219 \\
\hline \multicolumn{5}{|l|}{ Weekends } \\
\hline Book reading (minutes/day) & $60(13,120)$ & $60(12,120)$ & $60(12,120)$ & 0.108 \\
\hline TV/DVD watching (minutes/day) & $33(6,120)$ & $42(12,120)$ & $60(12,150)$ & 0.023 \\
\hline${ }^{\circ}$ Electronic games /internet use (minutes/day) & $0(0,30)$ & $0(0,30)$ & $0(0,30)$ & 0.222 \\
\hline *All media (minutes/day) & $51(12,150)$ & $60(12,120)$ & $60(12,150)$ & 0.049 \\
\hline Middle sleep (HH:MM) & $05: 24(00: 57)$ & $05: 23(00: 53)$ & $05: 17(00: 53)$ & 0.466 \\
\hline Sleep duration (HH:MM) & $10: 48(01: 54)$ & $10: 48(01: 45)$ & $10: 36(01: 45)$ & 0.576 \\
\hline \multicolumn{5}{|l|}{ Week } \\
\hline Book reading (minutes/day) & $60(24,120)$ & $42(12,90)$ & $42(12,120)$ & 0.128 \\
\hline TV/DVD watching (minutes/day) & $30(0,90)$ & $30(0,85)$ & $30(0,90)$ & 0.437 \\
\hline${ }^{\circ}$ Electronic games /internet use (minutes/day) & $0(0,12)$ & $0(0,12)$ & $0(0,30)$ & 0.257 \\
\hline *All media (minutes/day) & $30(0,90)$ & $30(0,90)$ & $30(0,120)$ & 0.254 \\
\hline Middle sleep (HH:MM) & $05: 23(00: 55)$ & $05: 20(00: 48)$ & $05: 13(00: 45)$ & 0.478 \\
\hline Sleep duration (HH:MM) & $10: 48(01: 50)$ & $10: 42(01: 35)$ & $10: 24(01: 30)$ & 0.579 \\
\hline
\end{tabular}

Notes: Data reported as median (10th-90th percentiles), 'Use of computer, tablets, DVD or mobile phones, *Computed as the sum of TV/DVD watching and use of electronic devices or internet use. Bold Represents Significant P-value $(\alpha=0.05)$. 


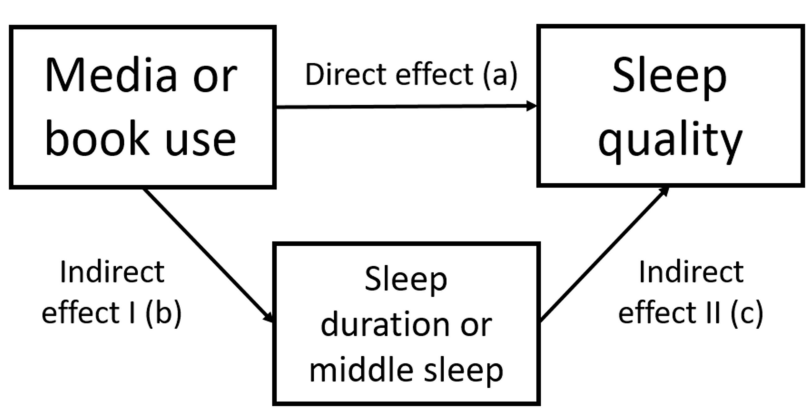

Figure I Diagram of mediation model used.

sleep as mediators of the relation between media use or book reading and sleep quality (Figure 1). Direct and indirect effects were reported as standardized and rescaled regression coefficients. The total effect of media use or book reading on sleep quality was computed as: total effect $=a+b * c$, where the term "a" was the slope of the direct effect, while the terms "b" and "c" were the slopes of the indirect effects.

On the basis of this causal path model, the different time points from the repeated measures within SPATZ were taken into account considering four different causal models having a first order autoregressive structure. The first model (Model A) considered the prospective relation of media use or book reading with sleep quality (direct effect) and with the mediators sleep duration or midpoint of sleep (indirect effect I) between ages $4 / 5$ and 5/6 years. In this model, the effect of sleep duration or midpoint of sleep on sleep quality (indirect effect II) was crosssectional. The second model (Model B) included only a prospective direct effect between ages $4 / 5$ and $5 / 6$ years while all indirect effects were cross-sectional. The last two models (Models $\mathrm{C}$ and D) had all effects as crosssectional considering the data collected at ages $4 / 5$ and at ages $5 / 6$, respectively. Diagrams of the four causal path models are reported in Supplementary Figure 1.

Finally, a sensitivity analysis was conducted in the form of a fully prospective model. Here, we modeled (i) the relation between media use or book reading at age 4 years with child sleep quality at age 6 years (direct effect), (ii) the relation between media use or book reading (age 4 years) on sleep duration or midpoint of sleep at age 5 years (indirect effect I), and (iii) the relation between sleep duration or midpoint of sleep (age 5 years) on sleep quality (age 6 years; indirect effect II).

All analyses were conducted separately for weekends and weekdays using the respective data. All models were adjusted for maternal age and education as a proxy for socio-economic status. Sensitivity analyses to investigate residual confounding were performed adjusting for the child's diet, physical activity, body size (triponderal mass index), and season of birth which also correspond to the season of assessment (yearly questionnaires were administered at or around the birthday). All the statistical tests were two-tailed and the type-I error rate was set to $5 \%(\alpha$ $=0.05)$. The LAVAAN package of $\mathrm{R}$ software version 3.6 was used to conduct the mediation analysis. A posteriori power calculation was performed using the SHINY package of R software version $3.6 .{ }^{25}$

\section{Results}

After data management, check for data quality, and deleting subjects with missing values for covariates and outcome variables, the three SPATZ datasets at ages 4,5 , and 6 years had 442, 403, and 359 records, respectively. Merging the three datasets resulted in an analytical dataset of 563 records, overall. Matching the data at ages 4 and 5, 5 and 6, and 4 and 6 years resulted in 312, 276, and 279 records, respectively. The baseline median age of the mothers was 33 years, ranging between 21 and 54 years, while the median baseline age of the fathers was 35 (10th to 90th range $=29,43)$. The majority of parents had a good job position and education level with $50 \%$ having a managerial or higher professional job and at least a high school degree. Among children, the girl-to-boy ratio was constant over the sample from the three SPATZ waves (Girls to Boy $=0.94,0.91$ and 0.92 for the SPATZ waves 6,7 and 8 , respectively). When looking at body mass index (BMI), we observed a median BMI of 23.4 (10th to 90th range $=19.4,31.6)$ and 25.3 (10th to 90th range $=21.9,30.0$ ) for mothers and fathers, respectively. As depicted in Table 1, the overall distribution of sleep quality scores appeared stable across the three time points, and no differences were observed when comparing distributions of sleep quality scores between weekends and weekdays. The observed mean of the CSHQ overall score in our sample ranged between 42 and 43, comparable to that of the German sample (Normal children age 410) used for the validation of the questionnaire. ${ }^{22}$ In contrast, overall media use and TV/DVD watching on the weekends increased significantly over the three time points, while book reading again seemed stable Overall, book reading and media use occupied more time per day on weekends. In general, TV/DVD watching represented more than $70 \%$ of the time spent with media use, 
regardless of age or weekday/weekend. Further details on sleep quality, media use, book reading, sleep duration and midpoint of sleep on weekdays and on weekends (free days) are given by age in Table 1 .

As shown in Table 2 and Figure 2, on the one hand, we observed weak, borderline significant correlation between media use of all kinds and sleep quality scores $(\mathrm{R}=0.08$ to $0.20)$. On the other hand, we found a negative correlation of sleep duration and midpoint of sleep during weekdays with sleep quality at ages 4 and 5 years $(\mathrm{R}=-0.21$ to $-0.10)$, while this correlation was attenuated and no longer significant at age 6 years ( $R=-0.05$ to 0.03 ). The same pattern, albeit with weaker correlations, was observed during weekends. Moreover, the two potential mediators, sleep duration and midpoint of sleep, were strongly positively correlated $(\mathrm{R}=0.90$ to 0.95 for ages 4,5 and 6 years on weekdays and $\mathrm{R}=0.70$ to 0.75 for ages 4 and 5 years on weekends, $R=0.55$ for age 6 years on weekends).

In the causal mediation analyses (Tables 2-5), we generally observed that significant effects were present for total digital media use and TV/DVD watching, while digital gaming and book reading did not affect sleep quality, sleep duration and midpoint of sleep. Moreover, there was little evidence for mediation of the effect of media use on sleep quality via sleep duration or midpoint of sleep. This indicates that media use acts independently on sleep duration, midpoint of sleep, and sleep quality. Also, the non-statistically significant effects of sleep duration and midpoint of sleep on sleep quality score indicate that sleep quality, sleep quantity, and the midpoint of sleep appear as uncorrelated aspects of sleep adequacy. The observed effects tended to be stronger during weekends than during the weekdays. Finally, results from the four different causal mediation models suggested that media use acted on sleep quality through a direct prospective from age 4 years to age 5 years and only for digital media use and not for book reading (Tables 2 and 3). Of note, this effect was not detected when considering TV/DVD use or electronic gaming and internet use separately. Similar to the prospective models (Tables 2 and 3), the cross-sectional analyses (Tables 4 and 5) showed significant associations of media use with sleep duration and with the midpoint of sleep at ages 4 and 5 years.

Sensitivity analysis using the fully prospective model confirmed the observed indirect effect of media use with sleep duration and midpoint of sleep, while no statistically significant direct effect between media use at age 4 years and sleep quality at age 6 years was observed (data not shown). The aforementioned results were substantiated in models further adjusted for diet, physical activity, body size, and seasonality (data not shown).

\section{Discussion}

In the present German cohort study of preschoolers, electronic media use was associated with impaired sleep quality in longitudinal analyses. In parallel, media use also affected sleep duration and midpoint of sleep. These results are in line with observations made in studies on toddlers, preschoolers and adolescents..$^{9,15,16,20,26,27}$ Our analyses only weakly support an indirect effect of electronic media use on sleep quality mediated through sleep duration or midpoint of sleep. If we accept the speculation of considering the midpoint of sleep of free days as a chronotype proxy, we may infer that media use affects sleep quality, sleep quantity, and chronotype, while the latter two are strongly related to each other. This result was confirmed in a previous study in which both chronotype and media use were statistically related to sleep quality when present in the same regression model applied to healthy, school-age children. ${ }^{28}$

Investigating the different time points, we detected a significant prospective direct effect between electronic media use at age 4 years and sleep quality at age 5 years but not between media use at age 5 and sleep quality at age 6 years. This went along with an effect of media use at age 4 years on sleep quantity and on the midpoint of sleep at ages 4 and 5 years. Moreover, a cross-sectional effect of media use on sleep quantity and midpoint of sleep was observed at ages 4 and 5 but not at age 6 years. Thus, it is possible that electronic media use affects sleep quality in the long term, but only between the ages of 4 and 5 years, while the effects of media use on sleep duration are observed more in the short term or cross-sectionally at the ages of 4 and 5 years. According to our results, the effect of digital media use on sleep quality, sleep quantity, and midpoint of sleep is stronger in children up to the age of 5 years.

The current results possibly support an inverse doseresponse relation between media use, sleep quality, and age with higher susceptibility to media use in younger children. This observation in longitudinal data of preschool children is novel but not surprising. On the one hand, a similar inverse dose-response association was previously observed crosssectionally in toddlers and young adolescents with odds ratios of reduced sleep quantity in relation to increased media use of 2.4 and 1.6, respectively. ${ }^{26,27}$ On the other hand, our study, 
Table 2 Standardized Regression Coefficients of Mediation Analysis Applied to Sleep Quality Score, Media Use or Book Reading and Sleep Duration or Middle Sleep

\begin{tabular}{|c|c|c|c|c|}
\hline & Direct Effect & Indirect Effect I & Indirect Effect II & Total Effect \\
\hline \multicolumn{5}{|l|}{ Free days } \\
\hline $\mathrm{SCC} 8 \leftarrow \mathrm{TP} 7+\mathrm{SD} 7$ & $0.025(0.049)$ & $-0.015(0.063)$ & $0.059(0.05 \mathrm{I})$ & $0.024(0.049)$ \\
\hline $\mathrm{SCC} 7 \leftarrow \mathrm{TP} 6+\mathrm{SD} 6$ & $0.096(0.047)$ & $-0.152(0.064)$ & $0.096(0.047)$ & $0.100(0.047)$ \\
\hline $\mathrm{SCC} 8 \leftarrow \mathrm{TP7}+\mathrm{MS7}$ & $0.025(0.049)$ & $-0.020(0.063)$ & $0.056(0.05 \mathrm{I})$ & $0.024(0.049)$ \\
\hline $\mathrm{SCC} 7 \leftarrow \mathrm{TP} 6+\mathrm{MS} 6$ & $0.096(0.047)$ & $-0.145(0.064)$ & $-0.030(0.048)$ & $0.100(0.047)$ \\
\hline $\mathrm{SCC} 8 \leftarrow \mathrm{BK} 7+\mathrm{SD} 7$ & $-0.014(0.047)$ & $0.030(0.062)$ & $0.068(0.05 \mathrm{I})$ & $-0.012(0.048)$ \\
\hline $\mathrm{SCC} 7 \leftarrow \mathrm{BK} 6+\mathrm{SD} 6$ & $-0.048(0.045)$ & $0.04 I(0.064)$ & $-0.04 I(0.048)$ & $-0.050(0.046)$ \\
\hline $\mathrm{SCC} 8 \leftarrow \mathrm{BK} 7+\mathrm{MS7}$ & $-0.014(0.047)$ & $0.031(0.062)$ & $0.065(0.050)$ & $-0.012(0.048)$ \\
\hline $\mathrm{SCC} 7 \leftarrow \mathrm{BK} 6+\mathrm{MS} 6$ & $-0.048(0.045)$ & $0.038(0.064)$ & $-0.046(0.048)$ & $-0.050(0.046)$ \\
\hline $\mathrm{SCC} 8 \leftarrow \mathrm{PC} 7+\mathrm{SD} 7$ & $-0.015(0.046)$ & $-0.039(0.06 \mathrm{I})$ & $0.06 \mathrm{I}(0.05 \mathrm{I})$ & $-0.018(0.046)$ \\
\hline $\mathrm{SCC} 7 \leftarrow \mathrm{PC} 6+\mathrm{SD} 6$ & $0.049(0.047)$ & $0.041(0.063)$ & $-0.042(0.048)$ & $0.048(0.047)$ \\
\hline $\mathrm{SCC} 8 \leftarrow \mathrm{PC} 7+\mathrm{MS7}$ & $-0.016(0.046)$ & $-0.037(0.062)$ & $0.058(0.05 \mathrm{I})$ & $-0.018(0.046)$ \\
\hline $\mathrm{SCC} 7 \leftarrow \mathrm{PC} 6+\mathrm{MS} 6$ & $0.050(0.047)$ & $0.043(0.063)$ & $-0.046(0.048)$ & $0.048(0.047)$ \\
\hline $\mathrm{SCC} 8 \leftarrow \mathrm{TV} 7+\mathrm{SD} 7$ & $0.052(0.048)$ & $-0.018(0.06 \mathrm{I})$ & $0.060(0.05 \mathrm{I})$ & 0.05 I (0.048) \\
\hline $\mathrm{SCC} 7 \leftarrow \mathrm{TV} 6+\mathrm{SD} 6$ & $0.100(0.047)$ & $-0.173(0.062)$ & $-0.026(0.048)$ & $0.104(0.047)$ \\
\hline SCC8 $\leftarrow$ TV7 + MS7 & $0.053(0.048)$ & $-0.023(0.06 \mathrm{I})$ & $0.057(0.050)$ & 0.05 I (0.048) \\
\hline $\mathrm{SCC} 7 \leftarrow \mathrm{TV} 6+\mathrm{MS} 6$ & $0.099(0.047)$ & $-0.167(0.062)$ & $-0.030(0.048)$ & $0.104(0.047)$ \\
\hline \multicolumn{5}{|l|}{ Working Days } \\
\hline $\mathrm{SCC} 8 \leftarrow \mathrm{TP} 7+\mathrm{SD} 7$ & $0.045(0.052)$ & $-0.110(0.066)$ & $-0.070(0.050)$ & $0.052(0.053)$ \\
\hline $\mathrm{SCC} 7 \leftarrow \mathrm{TP} 6+\mathrm{SD} 6$ & $0.077(0.050)$ & $-0.221(0.067)$ & $-0.08 \mathrm{I}(0.047)$ & $0.095(0.050)$ \\
\hline $\mathrm{SCC} 8 \leftarrow \mathrm{TP7}+\mathrm{MS7}$ & $0.044(0.052)$ & $-0.112(0.065)$ & $-0.074(0.050)$ & $0.053(0.053)$ \\
\hline $\mathrm{SCC} 7 \leftarrow \mathrm{TP} 6+\mathrm{MS} 6$ & $0.077(0.050)$ & $-0.221(0.066)$ & $-0.083(0.047)$ & $0.095(0.050)$ \\
\hline $\mathrm{SCC} 8 \leftarrow \mathrm{BK} 7+\mathrm{SD} 7$ & $-0.017(0.046)$ & $0.082(0.063)$ & $-0.068(0.050)$ & $-0.023(0.046)$ \\
\hline $\mathrm{SCC} 7 \leftarrow \mathrm{BK} 6+\mathrm{SD} 6$ & $-0.033(0.046)$ & $0.041(0.065)$ & $-0.089(0.046)$ & $-0.037(0.047)$ \\
\hline $\mathrm{SCC} 8 \leftarrow \mathrm{BK} 7+\mathrm{MS} 7$ & $-0.017(0.046)$ & $0.082(0.062)$ & $-0.072(0.050)$ & $-0.023(0.046)$ \\
\hline $\mathrm{SCC} 7 \leftarrow \mathrm{BK} 6+\mathrm{MS} 6$ & $-0.034(0.046)$ & $0.039(0.065)$ & $-0.093(0.047)$ & $-0.037(0.047)$ \\
\hline $\mathrm{SCC} 8 \leftarrow \mathrm{PC} 7+\mathrm{SD} 7$ & $-0.016(0.045)$ & $0.020(0.064)$ & $-0.069(0.050)$ & $-0.018(0.045)$ \\
\hline $\mathrm{SCC} 7 \leftarrow \mathrm{PC} 6+\mathrm{SD} 6$ & $0.059(0.044)$ & $-0.036(0.066)$ & $-0.090(0.046)$ & $0.063(0.044)$ \\
\hline $\mathrm{SCC} 8 \leftarrow \mathrm{PC} 7+\mathrm{MS7}$ & $-0.016(0.045)$ & $0.025(0.063)$ & $-0.073(0.050)$ & $-0.018(0.046)$ \\
\hline $\mathrm{SCC} 7 \leftarrow \mathrm{PC} 6+\mathrm{MS} 6$ & $0.060(0.044)$ & $-0.033(0.065)$ & $-0.093(0.046)$ & $0.063(0.044)$ \\
\hline $\mathrm{SCC} 8 \leftarrow \mathrm{TV} 7+\mathrm{SD} 7$ & $0.014(0.05 \mathrm{I})$ & $-0.103(0.065)$ & $-0.072(0.050)$ & $0.02 I(0.05 I)$ \\
\hline $\mathrm{SCC} 7 \leftarrow \mathrm{TV} 6+\mathrm{SD} 6$ & $0.056(0.048)$ & $-0.216(0.066)$ & $-0.080(0.047)$ & $0.073(0.048)$ \\
\hline $\mathrm{SCC} 8 \leftarrow \mathrm{TV} 7+\mathrm{MS7}$ & $0.014(0.051)$ & $-0.107(0.064)$ & $-0.076(0.050)$ & $0.022(0.05 \mathrm{I})$ \\
\hline $\mathrm{SCC} 7 \leftarrow \mathrm{TV} 6+\mathrm{MS} 6$ & $0.055(0.048)$ & $-0.216(0.066)$ & $-0.083(0.047)$ & $0.073(0.048)$ \\
\hline
\end{tabular}

Notes: Direct effect: Sleep quality score (SCCx) $\leftarrow$ media use (TPx: all media, PCx: computer games or internet, TVx: Television watching) or book reading (BKx); Indirect effect I: Sleep duration (SDx) or middle sleep (MSx) $\leftarrow$ m media use (TPx: all media, PCx: computer games or internet, TVx: Television watching) or book reading (BKx)); Indirect effect II: sleep quality score (SCCx) $\leftarrow$ Sleep duration (SDx) or middle sleep (MSx); Total effect; $\mathrm{x}$ : SPATZ study wave. Results from Model A. Bold Represents Significant P-value $(\alpha=0.05)$.

along with others, supports a strong correlation between sleep quantity and sleep quality. ${ }^{1,29,30}$ Hence, it was likely that the observed inverse association between media use, sleep quality and age may have acted through the sleep quantity of the children. However, our structural equation models do not strongly support the idea of effects of media use on sleep quality mediated by sleep quantity.

In the present work, we reported a non-significant correlation between book reading and sleep quality score.
This result is apparently in contrast to current ideas for which active or passive reading is a recommended practice for preschoolers. ${ }^{10,31}$

Finally, most of the associations appeared to be stronger during the weekends. This could be due to two possible reasons. Firstly, child sleep is likely influenced by the parents' working routine. Secondly, we documented higher electronic media use during the weekend so that the stronger evidence of an association 


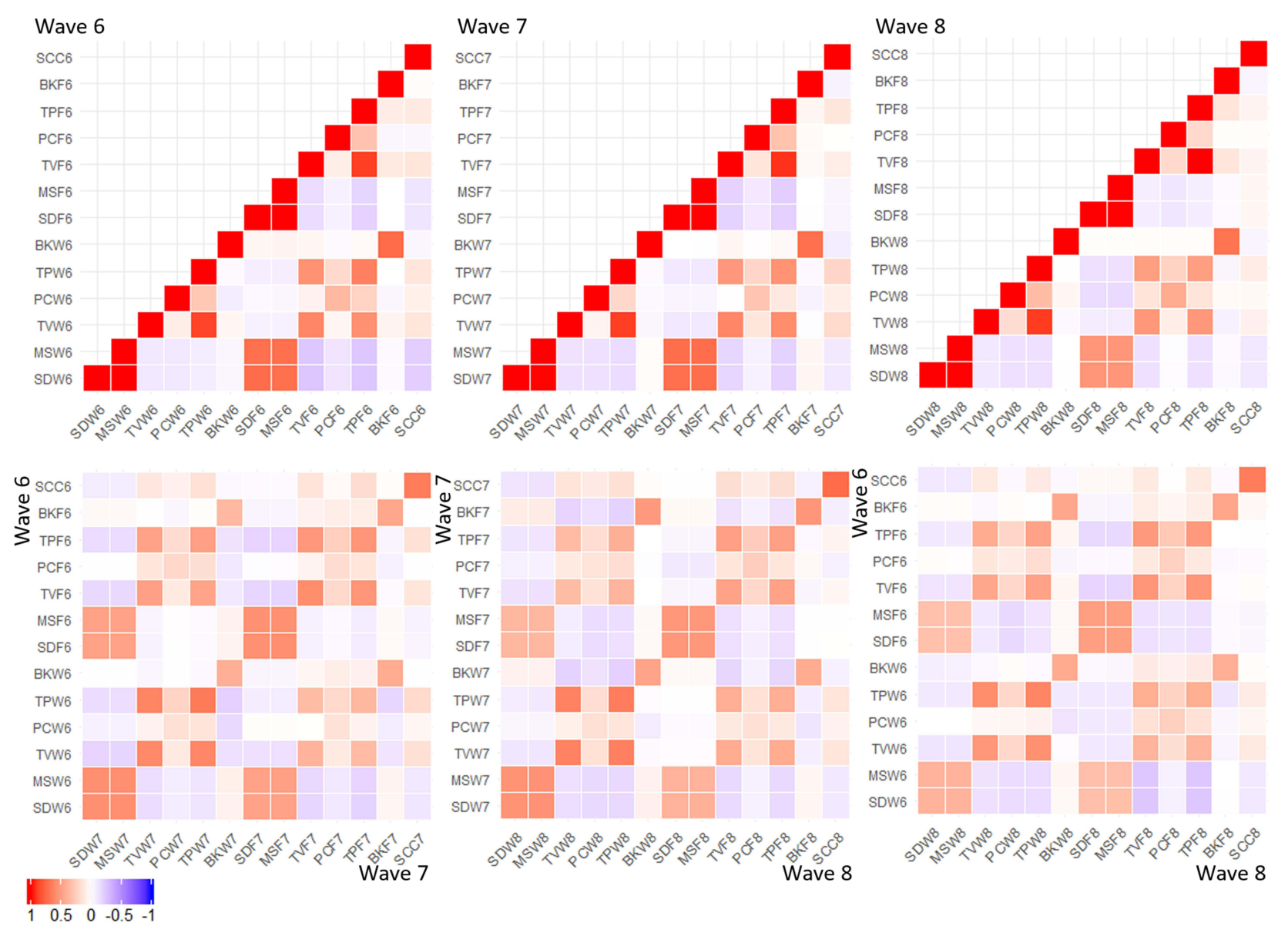

Figure 2 Heat maps of Pearson correlation coefficients of Blom's transformed variables.

Abbreviations: SQ, sleep quality score; BK, book reading; AM, all media use; PC, use of personal computer or video games; TV, TV or DVD watching; MS, midpoint of sleep; SD, sleep duration; suffix F, free days (weekend); suffix W, weekday; suffix 6-7-8, study wave.

between media use and sleeping could be due to a doseresponse relation, which would be in agreement with previous studies. $^{32,33}$

\section{Strengths and Limitations}

The present work has many strengths. To our knowledge, this is the first prospective study aimed to understand direct and indirect effects of media use on sleep quality, sleep quantity, and midpoint of sleep of preschoolers. Simultaneously evaluating all these aspects of sleep in the same models goes beyond previously reported studies. Moreover, the current work investigates sleep in relation to media use separately on weekends and parents' working days evaluating the role of parents' working routine on child's sleep. Still, the limited sample size may have influenced our results, leading to limited statistical power and thus false negative results. However, in the absence of clear a-priori evidence for statistical effects, we were able to perform only a posteriori power calculation which confirmed that the sample size used (250 to 300 units) was sufficient $(1-\beta \geq 0.8$, statistical power $>80 \%$ ) to detect an effect size of at least 0.2 correlation unit with the observed standard error. Further possible limitations include measurement error or even self-report bias due to the use of selfadministered questionnaires. More specifically, we cannot exclude a possible bias due to the high probability that parents underreport media use and might over-report on activities like book reading. While such questionnairebased assessment is common to most previous studies, novel tools integrating sensing technology and diarybased methods are being developed and could be useful for future work. Moreover, our work, like many observational studies, could have been possibly affected by misreporting or other forms of biases. For example, while a child can pick a book media use is less under their 
Table 3 Standardized Regression Coefficients of Mediation Analysis Applied to Sleep Quality Score, Media Use or Book Reading and Sleep Duration or Middle Sleep

\begin{tabular}{|c|c|c|c|c|}
\hline & Direct Effect & Indirect Effect I & Indirect Effect II & Total Effect \\
\hline \multicolumn{5}{|l|}{ Free days } \\
\hline SCC8 $\leftarrow$ TP7 + SD8 & $0.028(0.050)$ & $-0.187(0.056)$ & $0.017(0.050)$ & $0.025(0.049)$ \\
\hline $\mathrm{SCC} 7 \leftarrow \mathrm{TP} 6+\mathrm{SD} 7$ & $0.108(0.048)$ & $-0.143(0.053)$ & $0.002(0.05 I)$ & $0.108(0.047)$ \\
\hline $\mathrm{SCC} 8 \leftarrow \mathrm{TP7}+\mathrm{MS8}$ & $0.028(0.050)$ & $-0.179(0.056)$ & $0.021(0.050)$ & $0.024(0.049)$ \\
\hline $\mathrm{SCC} 7 \leftarrow \mathrm{TP} 6+\mathrm{MS7}$ & $0.107(0.048)$ & $-0.143(0.053)$ & $-0.007(0.015)$ & $0.107(0.047)$ \\
\hline SCC8 $\leftarrow \mathrm{BK} 7+\mathrm{SD} 8$ & $-0.012(0.048)$ & $-0.037(0.055)$ & $0.023(0.050)$ & $-0.013(0.048)$ \\
\hline $\mathrm{SCC} 7 \leftarrow \mathrm{BK} 6+\mathrm{SD} 7$ & $-0.044(0.046)$ & $0.017(0.052)$ & $-0.019(0.050)$ & $-0.044(0.046)$ \\
\hline $\mathrm{SCC} 8 \leftarrow \mathrm{BK} 7+\mathrm{MS} 8$ & $-0.013(0.048)$ & $-0.040(0.055)$ & $0.027(0.050)$ & $-0.014(0.048)$ \\
\hline $\mathrm{SCC} 7 \leftarrow \mathrm{BK} 6+\mathrm{MS7}$ & $-0.044(0.046)$ & $0.014(0.052)$ & $-0.023(0.050)$ & $-0.044(0.046)$ \\
\hline SCC8 $\leftarrow \mathrm{PC7}+\mathrm{SD} 8$ & $-0.017(0.046)$ & $-0.008(0.053)$ & $0.024(0.050)$ & $-0.017(0.046)$ \\
\hline $\mathrm{SCC} 7 \leftarrow \mathrm{PC} 6+\mathrm{SD} 7$ & $0.052(0.047)$ & $-0.111(0.054)$ & $-0.013(0.050)$ & $0.053(0.047)$ \\
\hline $\mathrm{SCC} 8 \leftarrow \mathrm{PC} 7+\mathrm{MS} 8$ & $-0.018(0.046)$ & $-0.008(0.053)$ & $0.029(0.050)$ & $0.018(0.046)$ \\
\hline $\mathrm{SCC} 7 \leftarrow \mathrm{PC} 6+\mathrm{MS7}$ & 0.05 I (0.047) & $-0.109(0.054)$ & $-0.018(0.050)$ & $0.053(0.047)$ \\
\hline $\mathrm{SCC} 8 \leftarrow \mathrm{TV} 7+\mathrm{SD} 8$ & $0.055(0.049)$ & $-0.180(0.054)$ & $0.020(0.050)$ & $0.052(0.048)$ \\
\hline $\mathrm{SCC7} \leftarrow \mathrm{TV} 6+\mathrm{SD} 7$ & $0.111(0.047)$ & $-0.125(0.053)$ & $0.001(0.05 I)$ & $0.111(0.047)$ \\
\hline $\mathrm{SCC} 8 \leftarrow \mathrm{TV} 7+\mathrm{MS} 8$ & $0.055(0.049)$ & $-0.172(0.054)$ & $0.024(0.050)$ & 0.05 I (0.048) \\
\hline $\mathrm{SCC} 7 \leftarrow \mathrm{TV} 6+\mathrm{MS7}$ & $0.109(0.047)$ & $-0.125(0.053)$ & $-0.004(0.050)$ & $0.110(0.047)$ \\
\hline \multicolumn{5}{|l|}{ Working Days } \\
\hline $\mathrm{SCC} 8 \leftarrow \mathrm{TP7}+\mathrm{SD} 8$ & $0.039(0.053)$ & $-0.186(0.059)$ & $-0.044(0.049)$ & $0.047(0.052)$ \\
\hline $\mathrm{SCC} 7 \leftarrow \mathrm{TP} 6+\mathrm{SD} 7$ & $0.086(0.050)$ & $-0.143(0.055)$ & $-0.04 \mathrm{I}(0.050)$ & $0.092(0.050)$ \\
\hline $\mathrm{SCC} 8 \leftarrow \mathrm{TP7}+\mathrm{MS8}$ & $0.039(0.053)$ & $-0.184(0.059)$ & $-0.047(0.050)$ & $0.047(0.052)$ \\
\hline $\mathrm{SCC} 7 \leftarrow \mathrm{TP} 6+\mathrm{MS7}$ & $0.085(0.050)$ & $-0.146(0.055)$ & $-0.045(0.050)$ & $0.092(0.050)$ \\
\hline $\mathrm{SCC} 8 \leftarrow \mathrm{BK} 7+\mathrm{SD} 8$ & $-0.029(0.046)$ & $-0.068(0.054)$ & $-0.046(0.048)$ & $-0.025(0.046)$ \\
\hline $\mathrm{SCC} 7 \leftarrow \mathrm{BK} 6+\mathrm{SD} 7$ & $-0.046(0.047)$ & $-0.099(0.053)$ & $-0.062(0.050)$ & $-0.040(0.047)$ \\
\hline $\mathrm{SCC} 8 \leftarrow \mathrm{BK} 7+\mathrm{MS} 8$ & $-0.029(0.046)$ & $-0.074(0.053)$ & $-0.049(0.049)$ & $-0.026(0.046)$ \\
\hline $\mathrm{SCC} 7 \leftarrow \mathrm{BK} 6+\mathrm{MS7}$ & $-0.047(0.047)$ & $-0.100(0.053)$ & $-0.067(0.050)$ & $-0.040(0.047)$ \\
\hline $\mathrm{SCC} 8 \leftarrow \mathrm{PC} 7+\mathrm{SD} 8$ & $-0.020(0.045)$ & $-0.006(0.054)$ & $-0.042(0.049)$ & $-0.019(0.045)$ \\
\hline $\mathrm{SCC} 7 \leftarrow \mathrm{PC} 6+\mathrm{SD} 7$ & $0.059(0.044)$ & $-0.039(0.05 \mathrm{I})$ & -0.05 I (0.050) & $0.061(0.044)$ \\
\hline $\mathrm{SCC} 8 \leftarrow \mathrm{PC} 7+\mathrm{MS} 8$ & $-0.020(0.045)$ & $-0.003(0.053)$ & $-0.045(0.049)$ & $-0.019(0.045)$ \\
\hline $\mathrm{SCC} 7 \leftarrow \mathrm{PC} 6+\mathrm{MS7}$ & $0.058(0.044)$ & $-0.045(0.05 \mathrm{I})$ & $-0.055(0.050)$ & $0.061(0.044)$ \\
\hline SCC8 $\leftarrow$ TV7 + SD8 & $0.008(0.05 \mathrm{I})$ & $-0.170(0.058)$ & $-0.049(0.049)$ & $0.017(0.051)$ \\
\hline SCC7 $\leftarrow \mathrm{TV} 6+\mathrm{SD} 7$ & $0.066(0.048)$ & $-0.121(0.053)$ & $-0.044(0.050)$ & $0.07 \mid(0.048)$ \\
\hline SCC8 $\leftarrow$ TV7 + MS8 & $0.008(0.05 \mathrm{I})$ & $-0.170(0.058)$ & $-0.052(0.049)$ & $0.017(0.051)$ \\
\hline $\mathrm{SCC} 7 \leftarrow \mathrm{TV} 6+\mathrm{MS7}$ & $0.065(0.048)$ & $-0.124(0.053)$ & $-0.048(0.050)$ & 0.07 I (0.048) \\
\hline
\end{tabular}

Notes: Direct effect: Sleep quality score (SCCx) $\leftarrow$ media use (TPx: all media, PCx: computer games or internet, TVx: Television watching) or book reading (BKx); Indirect effect I: Sleep duration (SDx) or middle sleep (MSx) $\leftarrow$ m media use (TPx: all media, PCx: computer games or internet, TVx: Television watching) or book reading (BKx)); Indirect effect II: sleep quality score (SCCx) $\leftarrow$ Sleep duration (SDx) or middle sleep (MSx); $\mathrm{x}$ : SPATZ study wave. Results from Model B. Bold Represents Significant P-value $(\alpha=0.05)$.

control being controlled by parents. Furthermore, our study lacked accuracy since we did not collect information regarding parents work during the weekends. We cannot exclude that our work was affected by a possible residual confounding bias due to lack of adjustments related to fathers' features because of a strategical choice due to a number of missing values that would have affected the performances of our analysis. However, this choice seems as partially justifiable, according to previous evaluations pointing out a poor father's childcorrelation structure compared to the one between mother and child. ${ }^{34}$ Another important information that we did not consider was the use of social media for which the information was not specifically reported into our questionnaire. Nevertheless, we consider this to be a negligible source of bias since it does not seem very likely that preschoolers between the age of 4 to 6 years are using social media massively. Finally, we employed 
Table 4 Standardized Regression Coefficients of Mediation Analysis Applied to Sleep Quality Score, Media Use or Book Reading and Sleep Duration or Middle Sleep

\begin{tabular}{|c|c|c|c|c|}
\hline & Direct Effect & Indirect Effect I & Indirect Effect II & Total Effect \\
\hline \multicolumn{5}{|l|}{ Free days } \\
\hline SCC7 $\leftarrow$ TP7 + SD7 & $-0.001(0.044)$ & $-0.205(0.046)$ & $-0.052(0.044)$ & $0.009(0.043)$ \\
\hline $\mathrm{SCC} 6 \leftarrow \mathrm{TP} 6+\mathrm{SD} 6$ & $-0.009(0.044)$ & $-0.153(0.047)$ & $-0.010(0.043)$ & $-0.008(0.043)$ \\
\hline SCC7 $\leftarrow$ TP7 + MS7 & $-0.001(0.044)$ & $-0.199(0.046)$ & $-0.049(0.044)$ & $0.009(0.043)$ \\
\hline $\mathrm{SCC} 6 \leftarrow \mathrm{TP} 6+\mathrm{MS} 6$ & $-0.009(0.044)$ & $-0.153(0.048)$ & $-0.008(0.043)$ & $-0.008(0.043)$ \\
\hline SCC7 $\leftarrow \mathrm{BK} 7+\mathrm{SD} 7$ & $-0.037(0.042)$ & $-0.048(0.046)$ & $-0.056(0.043)$ & $-0.034(0.042)$ \\
\hline $\mathrm{SCC} 6 \leftarrow \mathrm{BK} 6+\mathrm{SD} 6$ & $0.05 \mathrm{I}(0.04 \mathrm{I})$ & $0.043(0.046)$ & $-0.015(0.043)$ & $0.050(0.04 I)$ \\
\hline $\mathrm{SCC} 7 \leftarrow \mathrm{BK} 7+\mathrm{MS7}$ & $-0.037(0.042)$ & $-0.049(0.046)$ & $-0.053(0.043)$ & $-0.034(0.042)$ \\
\hline $\mathrm{SCC} 6 \leftarrow \mathrm{BK} 6+\mathrm{MS} 6$ & $0.05 I(0.04 I)$ & $0.04 I(0.046)$ & $-0.013(0.043)$ & $0.050(0.04 I)$ \\
\hline $\mathrm{SCC} 7 \leftarrow \mathrm{PC7}+\mathrm{SD} 7$ & $0.016(0.041)$ & $-0.027(0.045)$ & $-0.050(0.044)$ & $0.017(0.04 I)$ \\
\hline $\mathrm{SCC} 6 \leftarrow \mathrm{PC} 6+\mathrm{SD} 6$ & $0.031(0.04 I)$ & $-0.070(0.046)$ & $-0.007(0.043)$ & $0.03 I(0.04 I)$ \\
\hline $\mathrm{SCC7} \leftarrow \mathrm{PC7}+\mathrm{MS7}$ & $0.016(0.041)$ & $-0.029(0.045)$ & $-0.048(0.044)$ & $0.017(0.041)$ \\
\hline $\mathrm{SCC} 6 \leftarrow \mathrm{PC} 6+\mathrm{MS} 6$ & $0.031(0.04 I)$ & $-0.067(0.046)$ & $-0.005(0.043)$ & $0.03 I(0.04 I)$ \\
\hline SCC7 $\leftarrow$ TV7 + SD7 & $0.008(0.044)$ & $-0.201(0.047)$ & $-0.049(0.044)$ & $0.018(0.043)$ \\
\hline $\mathrm{SCC} 6 \leftarrow \mathrm{TV} 6+\mathrm{SD} 6$ & $-0.016(0.043)$ & $-0.132(0.047)$ & $-0.011(0.043)$ & $-0.015(0.043)$ \\
\hline SCC7 $\leftarrow \mathrm{TV} 7+\mathrm{MS7}$ & $0.009(0.044)$ & $-0.194(0.047)$ & $-0.047(0.044)$ & $0.018(0.043)$ \\
\hline $\mathrm{SCC} 6 \leftarrow \mathrm{TV} 6+\mathrm{MS} 6$ & $-0.016(0.043)$ & $-0.132(0.047)$ & $-0.009(0.043)$ & $-0.015(0.043)$ \\
\hline \multicolumn{5}{|l|}{ Working Days } \\
\hline SCC7 $\leftarrow \mathrm{TP} 7+\mathrm{SD} 7$ & $0.149(0.044)$ & $-0.126(0.049)$ & $-0.072(0.042)$ & $0.158(0.044)$ \\
\hline $\mathrm{SCC} 6 \leftarrow \mathrm{TP} 6+\mathrm{SD} 6$ & $0.099(0.044)$ & $-0.117(0.049)$ & $-0.089(0.042)$ & $0.110(0.044)$ \\
\hline SCC7 $\leftarrow$ TP7 + MS7 & $0.148(0.044)$ & $-0.126(0.049)$ & $-0.076(0.042)$ & $0.158(0.044)$ \\
\hline $\mathrm{SCC} 6 \leftarrow \mathrm{TP} 6+\mathrm{MS} 6$ & $0.099(0.044)$ & $-0.121(0.048)$ & $-0.089(0.062)$ & $0.110(0.044)$ \\
\hline $\mathrm{SCC} 7 \leftarrow \mathrm{BK} 7+\mathrm{SD} 7$ & $-0.059(0.040)$ & $-0.060(0.046)$ & $-0.088(0.065)$ & $-0.054(0.040)$ \\
\hline $\mathrm{SCC} 6 \leftarrow \mathrm{BK} 6+\mathrm{SD} 6$ & $-0.013(0.043)$ & $-0.057(0.049)$ & $-0.102(0.059)$ & $-0.007(0.043)$ \\
\hline $\mathrm{SCC} 7 \leftarrow \mathrm{BK} 7+\mathrm{MS7}$ & $-0.059(0.040)$ & $-0.062(0.045)$ & $-0.091(0.062)$ & $-0.054(0.040)$ \\
\hline $\mathrm{SCC} 6 \leftarrow \mathrm{BK} 6+\mathrm{MS} 6$ & $-0.013(0.043)$ & $-0.060(0.048)$ & $-0.104(0.065)$ & $-0.007(0.043)$ \\
\hline $\mathrm{SCC7} \leftarrow \mathrm{PC7}+\mathrm{SD} 7$ & $0.015(0.038)$ & $-0.020(0.044)$ & $-0.087(0.063)$ & $0.016(0.039)$ \\
\hline $\mathrm{SCC} 6 \leftarrow \mathrm{PC} 6+\mathrm{SD} 6$ & $-0.031(0.040)$ & $-0.051(0.046)$ & $-0.099(0.075)$ & $-0.026(0.040)$ \\
\hline $\mathrm{SCC7} \leftarrow \mathrm{PC7}+\mathrm{MS7}$ & $0.015(0.038)$ & $-0.018(0.044)$ & $-0.091(0.068)$ & $0.016(0.039)$ \\
\hline $\mathrm{SCC} 6 \leftarrow \mathrm{PC} 6+\mathrm{MS} 6$ & $-0.032(0.040)$ & $-0.055(0.045)$ & $-0.100(0.088)$ & $-0.027(0.040)$ \\
\hline SCC7 $\leftarrow$ TV7 + SD7 & $0.106(0.043)$ & -0.111 ( 0.047$)$ & $-0.076(0.042)$ & $0.114(0.043)$ \\
\hline $\mathrm{SCC} 6 \leftarrow \mathrm{TV} 6+\mathrm{SD} 6$ & $0.048(0.043)$ & $-0.091(0.048)$ & $-0.096(0.085)$ & $0.056(0.044)$ \\
\hline SCC7 $\leftarrow$ TV7 + MS7 & $0.105(0.043)$ & $-0.111(0.047)$ & $-0.080(0.042)$ & $0.114(0.043)$ \\
\hline $\mathrm{SCC} 6 \leftarrow \mathrm{TV} 6+\mathrm{MS} 6$ & $0.047(0.043)$ & $-0.093(0.048)$ & $-0.097(0.042)$ & $0.057(0.044)$ \\
\hline
\end{tabular}

Notes: Direct effect: Sleep quality score (SCCx) $\leftarrow$ media use (TPx: all media, PCx: computer games or internet, TVx: Television watching) or book reading (BKx); Indirect effect l: Sleep duration (SDx) or middle sleep (MSx) $\leftarrow$ m media use (TPx: all media, PCx: computer games or internet, TVx: Television watching) or book reading (BKx)); Indirect effect II: sleep quality score (SCCx) $\leftarrow$ Sleep duration (SDx) or middle sleep (MSx); x: SPATZ study wave. Results from Model C. Bold Represents Significant P-value $(\alpha=0.05)$.

statistical analysis and an overall approach based on the assumption of causation. Assumptions of causation may not appear as epistemologically correct, especially because reverse causal effects or bi-directionality may exist since lack of sleep quantity or quality may have influenced digital media use. Nevertheless, we believe that the use of a prospective design may have limited, at least partially, this possible fallacy.

\section{Conclusions}

Electronic media use may have reduced sleep quantity and possibly compromised sleep quality in our sample of German preschoolers, especially before the age of 6 years. The present work may suggest that electronic media use is not a healthy entertainment for preschoolers, especially for doses as observed during weekends in the present study. 
Table 5 Standardized Regression Coefficients of Mediation Analysis Applied to Sleep Quality Score, Media Use or Book Reading and Sleep Duration or Middle Sleep

\begin{tabular}{|c|c|c|c|c|}
\hline & Direct Effect & Indirect Effect I & Indirect Effect II & Total Effect \\
\hline \multicolumn{5}{|l|}{ Free days } \\
\hline $\mathrm{SCC} 8 \leftarrow \mathrm{TP} 8+\mathrm{SD} 8$ & $0.012(0.050)$ & $-0.08 \mathrm{I}(0.057)$ & 0.07 I (0.05I) & $0.006(0.050)$ \\
\hline $\mathrm{SCC7} \leftarrow \mathrm{TP} 7+\mathrm{SD} 7$ & $0.054(0.048)$ & $-0.168(0.058)$ & $-0.031(0.047)$ & $0.059(0.048)$ \\
\hline $\mathrm{SCC} 8 \leftarrow \mathrm{TP} 8+\mathrm{MS} 8$ & $0.012(0.050)$ & $-0.084(0.057)$ & $0.067(0.05 \mathrm{I})$ & $0.006(0.050)$ \\
\hline $\mathrm{SCC} 7 \leftarrow \mathrm{TP7}+\mathrm{MS7}$ & $0.053(0.048)$ & $-0.160(0.058)$ & $-0.035(0.047)$ & $0.059(0.048)$ \\
\hline $\mathrm{SCC} 8 \leftarrow \mathrm{BK} 8+\mathrm{SD} 8$ & $0.020(0.047)$ & $-0.043(0.054)$ & $0.067(0.05 \mathrm{I})$ & $0.017(0.047)$ \\
\hline $\mathrm{SCC} 7 \leftarrow \mathrm{BK} 7+\mathrm{SD} 7$ & $-0.028(0.047)$ & $0.005(0.058)$ & $-0.038(0.047)$ & $-0.028(0.048)$ \\
\hline $\mathrm{SCC} 8 \leftarrow \mathrm{BK} 8+\mathrm{MS} 8$ & $0.020(0.047)$ & $-0.040(0.054)$ & $0.064(0.05 \mathrm{I})$ & $0.017(0.047)$ \\
\hline $\mathrm{SCC} 7 \leftarrow \mathrm{BK} 7+\mathrm{MS7}$ & $-0.028(0.047)$ & $0.002(0.058)$ & $-0.042(0.047)$ & $-0.028(0.048)$ \\
\hline $\mathrm{SCC} 8 \leftarrow \mathrm{PC} 8+\mathrm{SD} 8$ & $-0.066(0.045)$ & $-0.089(0.053)$ & $0.055(0.05 \mathrm{I})$ & $-0.071(0.044)$ \\
\hline $\mathrm{SCC} 7 \leftarrow \mathrm{PC} 7+\mathrm{SD} 7$ & $0.035(0.043)$ & $0.025(0.056)$ & $-0.04 I(0.047)$ & $0.034(0.043)$ \\
\hline $\mathrm{SCC} 8 \leftarrow \mathrm{PC} 8+\mathrm{MS} 8$ & $-0.066(0.045)$ & $-0.090(0.053)$ & $0.052(0.05 \mathrm{I})$ & $-0.07 \mid(0.044)$ \\
\hline $\mathrm{SCC} 7 \leftarrow \mathrm{PC} 7+\mathrm{MS7}$ & $0.035(0.043)$ & $0.025(0.056)$ & $-0.045(0.047)$ & $0.034(0.044)$ \\
\hline $\mathrm{SCC} 8 \leftarrow \mathrm{TV} 8+\mathrm{SD} 8$ & $0.008(0.050)$ & $-0.085(0.057)$ & $0.070(0.05 \mathrm{I})$ & $0.002(0.050)$ \\
\hline $\mathrm{SCC} 7 \leftarrow \mathrm{TV} 7+\mathrm{SD} 7$ & $0.044(0.047)$ & $-0.183(0.057)$ & $-0.031(0.048)$ & $0.049(0.046)$ \\
\hline $\mathrm{SCC} 8 \leftarrow \mathrm{TV} 8+\mathrm{MS} 8$ & $0.008(0.050)$ & $-0.088(0.057)$ & $0.067(0.05 \mathrm{I})$ & $0.002(0.050)$ \\
\hline SCC7 $\leftarrow$ TV7 + MS7 & $0.043(0.047)$ & $-0.175(0.057)$ & $-0.035(0.047)$ & $0.049(0.046)$ \\
\hline \multicolumn{5}{|l|}{ Working Days } \\
\hline $\mathrm{SCC} 8 \leftarrow \mathrm{TP} 8+\mathrm{SD} 8$ & $0.021(0.052)$ & $-0.047(0.058)$ & $-0.070(0.050)$ & $0.025(0.052)$ \\
\hline $\mathrm{SCC} 7 \leftarrow \mathrm{TP} 7+\mathrm{SD} 7$ & $0.102(0.052)$ & $-0.192(0.061)$ & $-0.076(0.046)$ & $0.117(0.05 I)$ \\
\hline $\mathrm{SCC} 8 \leftarrow \mathrm{TP} 8+\mathrm{MS} 8$ & $0.022(0.052)$ & $-0.043(0.058)$ & $-0.075(0.050)$ & $0.025(0.052)$ \\
\hline $\mathrm{SCC} 7 \leftarrow \mathrm{TP} 7+\mathrm{MS7}$ & $0.102(0.052)$ & $-0.188(0.061)$ & $-0.079(0.046)$ & $0.117(0.051)$ \\
\hline $\mathrm{SCC} 8 \leftarrow \mathrm{BK} 8+\mathrm{SD} 8$ & $-0.033(0.048)$ & $-0.052(0.056)$ & $-0.075(0.050)$ & $-0.029(0.048)$ \\
\hline $\mathrm{SCC} 7 \leftarrow \mathrm{BK} 7+\mathrm{SD} 7$ & $-0.035(0.046)$ & $-0.032(0.058)$ & $-0.093(0.046)$ & $-0.032(0.046)$ \\
\hline $\mathrm{SCC} 8 \leftarrow \mathrm{BK} 8+\mathrm{MS} 8$ & $-0.033(0.048)$ & $-0.047(0.055)$ & $-0.079(0.050)$ & $-0.029(0.048)$ \\
\hline $\mathrm{SCC} 7 \leftarrow \mathrm{BK} 7+\mathrm{MS7}$ & $-0.035(0.046)$ & $-0.033(0.057)$ & $-0.096(0.076)$ & $-0.032(0.046)$ \\
\hline $\mathrm{SCC} 8 \leftarrow \mathrm{PC} 8+\mathrm{SD} 8$ & $-0.030(0.046)$ & $-0.059(0.054)$ & $-0.073(0.050)$ & $-0.025(0.046)$ \\
\hline $\mathrm{SCC} 7 \leftarrow \mathrm{PC} 7+\mathrm{SD} 7$ & $0.028(0.044)$ & $-0.057(0.057)$ & $-0.089(0.046)$ & $0.033(0.044)$ \\
\hline $\mathrm{SCC} 8 \leftarrow \mathrm{PC} 8+\mathrm{MS} 8$ & $-0.030(0.046)$ & $-0.056(0.053)$ & $-0.077(0.050)$ & $-0.025(0.046)$ \\
\hline $\mathrm{SCC} 7 \leftarrow \mathrm{PC} 7+\mathrm{MS7}$ & $0.028(0.044)$ & $-0.056(0.056)$ & $-0.092(0.086)$ & $0.033(0.044)$ \\
\hline $\mathrm{SCC} 8 \leftarrow \mathrm{TV} 8+\mathrm{SD} 8$ & 0.04 I (0.049) & $-0.043(0.055)$ & $-0.069(0.050)$ & $0.044(0.049)$ \\
\hline $\mathrm{SCC} 7 \leftarrow \mathrm{TV} 7+\mathrm{SD} 7$ & $0.127(0.05 I)$ & $-0.184(0.061)$ & $-0.074(0.046)$ & $0.140(0.05 I)$ \\
\hline $\mathrm{SCC} 8 \leftarrow \mathrm{TV} 8+\mathrm{MS} 8$ & 0.041 (0.049) & $-0.040(0.054)$ & $-0.073(0.050)$ & $0.044(0.049)$ \\
\hline $\mathrm{SCC} 7 \leftarrow \mathrm{TV} 7+\mathrm{MS7}$ & $0.126(0.05 I)$ & $-0.181(0.060)$ & $-0.077(0.046)$ & $0.140(0.05 I)$ \\
\hline
\end{tabular}

Notes: Direct effect: Sleep quality score (SCCx) $\leftarrow$ media use (TPx: all media, PCx: computer games or internet, TVx: Television watching) or book reading (BKx); Indirect effect I: Sleep duration (SDx) or middle sleep (MSx) $\leftarrow$ m media use (TPx: all media, PCx: computer games or internet, TVx: Television watching) or book reading (BKx)); Indirect effect II: sleep quality score (SCCx) $\leftarrow$ Sleep duration (SDx) or middle sleep (MSx); $x$ : SPATZ study wave. Results from Model D. Bold Represents Significant P-value $(\alpha=0.05)$.

\section{Acknowledgments}

We thank the families for their participation in the Ulm SPATZ Health Study. We thank Jenny Radesky, University of Michigan, for expert comments on an earlier draft of this manuscript.

\section{Disclosure}

The authors report no conflicts of interest in this work.

\section{References}

1. Allen SL, Howlett MD, Coulombe JA, Corkum PV. ABCs of sleeping: a review of the evidence behind pediatric sleep practice recommendations. Sleep Med Rev. 2016;29:1-14. doi:10.1016/j. smrv.2015.08.006

2. Meltzer LJ, Williamson AA, Mindell JA. Pediatric sleep health: it matters, and so does how we define it. Sleep Med Rev. 2021a;57:101425. doi:10.1016/j.smrv.2021.101425

3. Meltzer LJ, Williamson AA, Mindell JA. Pediatric sleep health: it matters, and so does how we define it. Sleep Med Rev. 2021b;57:101425. doi:10.1016/j.smrv.2021.101425 
4. Carter KA, Hathaway NE, Lettieri CF. Common sleep disorders in children. Am Fam Physician. 2014;89(5):368-377.

5. Thiedke CC. Sleep disorders and sleep problems in childhood. Am Fam Physician. 2001;63(2):277-284.

6. Belmon LS, van Stralen MM, Busch V, Harmsen IA, Chinapaw MJM. What are the determinants of children's sleep behavior? A systematic review of longitudinal studies. Sleep Med Rev. 2019;43:60-70. doi:10.1016/j.smrv.2018.09.007

7. Kohlboeck G, Romanos M, Teuner CM, et al. Healthcare use and costs associated with children's behavior problems. Eur Child Adolesc Psychiatry. 2014;23(8):701-714. doi:10.1007/s00787-0130504-9

8. Cain N, Gradisar M. Electronic media use and sleep in school-aged children and adolescents: a review. Sleep Med. 2010;11(8):735-742. doi:10.1016/j.sleep.2010.02.006

9. Carter B, Rees P, Hale L, Bhattacharjee D, Paradkar MS. Association between portable screen-based media device access or use and sleep outcomes: a systematic review and meta-analysis. JAMA Pediatr. 2016;170(12):1202-1208. doi:10.1001/jamapediatrics.2016.2341

10. Hale L, Guan S. Screen time and sleep among school-aged children and adolescents: a systematic literature review. Sleep Med Rev. 2015;21:50-58. doi:10.1016/j.smrv.2014.07.007

11. Kabali HK, Irigoyen MM, Nunez-Davis R, et al. Exposure and use of mobile media devices by young children. Pediatrics. 2015;136 (6):1044-1050. doi:10.1542/peds.2015-2151

12. Marinelli M. Impact of television on the quality of sleep in preschool children. Sleep Med. 2016;20:138-139. doi:10.1016/j. sleep.2015.07.011

13. Brockmann PE, Diaz B, Damiani F, Villarroel L, Núñez F, Bruni O. Impact of television on the quality of sleep in preschool children. Sleep Med. 2016;20:140-144. doi:10.1016/j.sleep.2015.06.005

14. Garrison MM, Liekweg K, Christakis DA. Media use and child sleep: the impact of content, timing, and environment. Pediatrics. 2011;128 (1):29-35. doi:10.1542/peds.2010-3304

15. Hiltunen P, Leppänen MH, Ray C, et al. Relationship between screen time and sleep among Finnish preschool children: results from the DAGIS Study. Sleep Med. 2021;77:75-81. doi:10.1016/j. sleep.2020.11.008

16. Magee CA, Lee JK, Vella SA. Bidirectional relationships between sleep duration and screen time in early childhood. JAMA Pediatr. 2014;168(5):465-470. doi:10.1001/jamapediatrics.2013.4183

17. Mistry KB, Minkovitz CS, Strobino DM, Borzekowski DLG. Children's television exposure and behavioral and social outcomes at 5.5 years: does timing of exposure matter? Pediatrics. $2007 ; 120$ (4):762-769. doi:10.1542/peds.2006-3573

18. Paavonen EJ, Pennonen M, Roine M, Valkonen S, Lahikainen AR. TV exposure associated with sleep disturbances in 5- to 6-year-old children. J Sleep Res. 2006;15(2):154-161. doi:10.1111/j.13652869.2006.00525.x

19. Séguin D, Klimek V. Just five more minutes please: electronic media use, sleep and behaviour in young children. Early Child Dev Care. 2016;186(6):981-1000. doi:10.1080/03004430.2015.1071528

20. Zhang Z, Adamo KB, Ogden N, et al. Longitudinal correlates of sleep duration in young children. Sleep Med. 2021;78:128-134. doi:10.1016/j.sleep.2020.12.023
21. Janssen X, Martin A, Hughes AR, Hill CM, Kotronoulas G, Hesketh KR. Associations of screen time, sedentary time and physical activity with sleep in under $5 \mathrm{~s}$ : a systematic review and meta-analysis. Sleep Med Rev. 2020;49:101226. doi:10.1016/j. smrv.2019.101226

22. Schlarb AA, Schwerdtle B, Hautzinger M. Validation and psychometric properties of the German version of the children's sleep habits questionnaire (CSHQ-DE). Somnologie. 2010;14(4):260-266. doi:10.1007/s11818-010-0495-4

23. Werner H, Lebourgeois MK, Geiger A, Jenni OG. Assessment of chronotype in four- to eleven-year-old children: reliability and validity of the children's chronotype questionnaire (CCTQ). Chronobiol Int. 2009;26(5):992-1014. doi:10.1080/07420520903044505

24. Blom J. Statistical Estimates and Transformed Beta-variables. Vol. 3. 1961: 285.

25. Schoemann AM, Boulton AJ, Short SD. Determining power and sample size for simple and complex mediation models. Soc Psychol Personal Sci. 2017;8(4):379-386. doi:10.1177/1948550617715068

26. Brambilla P, Giussani M, Pasinato A, et al.; Ci piace sognare Study Group. Sleep habits and pattern in 1-14 years old children and relationship with video devices use and evening and night child activities. Ital J Pediatr. 2017;43(1):7. doi:10.1186/s13052-0160324-x

27. Chindamo S, Buja A, DeBattisti E, et al. Sleep and new media usage in toddlers. Eur J Pediatr. 2019;178(4):483-490. doi:10.1007/ s00431-019-03318-7

28. van der Heijden KB, Stoffelsen RJ, Popma A, Swaab H. Sleep, chronotype, and sleep hygiene in children with attention-deficit/ hyperactivity disorder, autism spectrum disorder, and controls. Eur Child Adolesc Psychiatry. 2018;27(1):99-111. doi:10.1007/s00787017-1025-8

29. Blunden S, Galland B. The complexities of defining optimal sleep: empirical and theoretical considerations with a special emphasis on children. Sleep Med Rev. 2014;18(5):371-378. doi:10.1016/j. smrv.2014.01.002

30. Lemola S, Räikkönen K, Scheier MF, et al. Sleep quantity, quality and optimism in children. J Sleep Res. 2011;20(1 Pt 1):12-20. doi: $10.1111 / j .1365-2869.2010 .00856 . x$

31. Mindell JA, Williamson AA. Benefits of a bedtime routine in young children: sleep, development, and beyond. Sleep Med Rev. 2018;40:93-108. doi:10.1016/j.smrv.2017.10.007

32. Tang L, Darlington G, Ma DWL, Haines J; Guelph Family Health Study. Mothers' and fathers' media parenting practices associated with young children's screen-time: a Cross-Sectional Study. BMC Obes. 2018;5:37.

33. Turnbull KLP, Alamos P, Williford AP, Downer JT. An exploration of electronic media use profiles for preschoolers of low-income families. Acad Pediatr. 2020;20(7):934-941. doi:10.1016/j. acap.2020.03.007

34. Ricci C, Parra-Robledo Z, Rothenbacher D, Díaz-Morales JF, Genuneit J. The parent's chronotype and child's sleeping quality in association with relationship satisfaction. Clocks Sleep. 2020;2 (3):375-389. doi:10.3390/clockssleep2030028
Nature and Science of Sleep

\section{Publish your work in this journal}

Nature and Science of Sleep is an international, peer-reviewed, open access journal covering all aspects of sleep science and sleep medicine, including the neurophysiology and functions of sleep, the genetics of sleep, sleep and society, biological rhythms, dreaming, sleep disorders and therapy, and strategies to optimize healthy sleep.
The manuscript management system is completely online and includes a very quick and fair peer-review system, which is all easy to use. Visit http://www.dovepress.com/testimonials.php to read real quotes from published authors. 